\title{
Treatment decisions in estrogen receptor-positive early breast cancer patients with intermediate oncotype DX recurrence score results
}

\author{
Georgeta Fried $^{*+}$ and Mor Moskovitz ${ }^{\dagger}$
}

\begin{abstract}
This retrospective study evaluated the impact of intermediate Recurrence Score ${ }^{\circledR}$ results on adjuvant treatment decisions in estrogen receptor-positive (ER+) early invasive breast cancer, comparing treatment recommendations pre-testing with actual treatments received post-testing. Of the 111 patients included in the analysis, 78 (70.3\%) had hormonal therapy $(\mathrm{HT})$ and 33 (29.7\%) had chemohormonal therapy (CHT) recommendations pre-testing. The Recurrence Score was significantly higher in those with a pre-testing $\mathrm{CHT}$ recommendation compared with those with a pre-testing HT recommendation (median of 24 vs. 22; $P=0.047$; Mann-Whitney-Wilcoxon [MWW] test). Post-testing, treatment of 24 patients (21.6\%) was different from their pre-testing recommendation. The difference between CHT recommendation rate pre-testing and the rate of $\mathrm{CHT}$ received post-testing was nonsignificant for the entire cohort and for patients' subgroups (by age, tumor size, and grade) ( $P>0.17$; McNemar's test). Following classification of the cohort into two Recurrence Score subcategories (low-intermediate, [18-25]; high-intermediate, [26-30]), changes in treatment decisions (pre-testing recommendations vs. actual treatments received post testing) were reported for $16.5 \%$ of low-intermediate and $34.4 \%$ of high-intermediate patients. Post-testing, the rate of $\mathrm{CHT}$ decreased (by 58\%) in the low-intermediate subcategory and increased (by 64\%) in the high-intermediate subcategory $(P<0.01$, both subcategories). In logistic regression analyses, the Recurrence Score subcategory was the only significant predictor of changes in treatment decisions (pre-testing recommendations vs. actual treatments received post testing; $P<0.01$ ). The only significant difference between the two subsets of patients with such a change (HT to CHT, 11 patients; CHT to HT, 13 patients) was the Recurrence Score (median of 28 vs. 20, respectively; $P=0.0014 ;$ MWW test). These findings demonstrate that intermediate Recurrence Score results provide clinically relevant information and impact treatment decisions in ER + early breast cancer.
\end{abstract}

Keywords: Adjuvant chemotherapy; Breast cancer; Decision making; Intermediate risk; Oncotype DX; Recurrence score

\section{Introduction}

The Oncotype DX ${ }^{\circledR}$ Breast Cancer assay (Genomic Health, Inc., Redwood City, CA) has been validated as a prognosticator and a predictor of the likelihood of chemotherapy benefit in estrogen receptor-positive (ER+) early invasive breast cancer (Paik et al. 2004; Paik et al. 2006; Habel et al. 2006; Goldstein et al. 2008; Albain et al. 2010; Dowsett et al. 2010; Toi et al. 2010; Mamounas et al. 2012). The Oncotype DX Recurrence Score ${ }^{\circledR}$ is a continuous value ranging from 0 to 100 ; it can be used to classify patients into 3 risk categories: low $(<18)$, intermediate

\footnotetext{
* Correspondence: g_fried@rambam.health.gov.il

${ }^{\dagger}$ Equal contributors

Rambam Health Care Campus, 6 Ha'Aliya Street, Haifa 31096, Israel
}

(18-30), and high ( $\geq 31)$ (Paik et al. 2004). For patients with high Recurrence Score results, the benefit from adjuvant chemotherapy is significant while for patients with low Recurrence Score results, there is minimal, if any, benefit from chemotherapy (Paik et al. 2006; Albain et al. 2010). In the intermediate Recurrence Score category, adjuvant chemotherapy may confer a modest benefit for some patients (Paik et al. 2006; Albain et al. 2010). Since becoming available in 2004, numerous studies conducted around the world (United States, European countries, Japan, Australia, and Israel) have investigated its impact on treatment decision-making in clinical practice and have consistently shown that testing results in a change in treatment recommendations in $19-51 \%$ of cases (from 
chemohormonal therapy to hormonal therapy alone and vice versa) correlating with a net reduction in chemotherapy use (Oratz et al. 2007; Asad et al. 2008; Rayhanabad et al. 2008; Henry et al. 2009; Klang et al. 2010; Lo et al. 2010; Ademuyiwa et al. 2011; de Boer et al. 2011; Geffen et al. 2011; Kamal et al. 2011; Oratz et al. 2011; Yamauchi et al. 2011; Albanell et al. 2012; Eiermann et al. 2012; Gligorov et al. 2012; Albanell et al. 2013; Holt et al. 2013). In the low Recurrence Score category (the largest category including $40-58 \%$ of patients in these studies), the recommendation change was mostly from chemohormonal therapy to hormonal therapy alone and in the high Recurrence Score category (the smallest category including $5-21 \%$ of patients in these studies), the recommendation change was mostly from hormonal therapy to chemohormonal therapy (Oratz et al. 2007; Klang et al. 2010; Lo et al. 2010; Ademuyiwa et al. 2011; Geffen et al. 2011; Oratz et al. 2011; Albanell et al. 2012; Eiermann et al. 2012; Gligorov et al. 2012; Albanell et al. 2013; Holt et al. 2013). In the intermediate Recurrence Score category, the observed changes in treatment recommendations were not consistent across studies, and data on the impact of the Recurrence Score and clinicopathologic characteristics on treatment recommendations in this subpopulation are limited (Oratz et al. 2007; Klang et al. 2010; Lo et al. 2010; Ademuyiwa et al. 2011; Geffen et al. 2011; Oratz et al. 2011; Albanell et al. 2012; Eiermann et al. 2012; Gligorov et al. 2012; Albanell et al. 2013; Holt et al. 2013). The current study was designed to evaluate the associations between Recurrence Score results and clinicopathologic characteristics in a cohort of patients with ER + early invasive breast cancer and an intermediate Recurrence Score result and to evaluate the impact of the Recurrence Score results and clinicopathologic characteristics on treatment decisions.

\section{Materials and methods Study design and patients}

This retrospective single-institution cohort study involving patients with ER + early invasive breast cancer and an intermediate Recurrence Score result included all female patients who were diagnosed and treated in the Rambam Health Care Campus (Haifa, Israel) between October 2005 and September 2010. The study was approved by the institutional review board of Rambam Health Care Campus.

\section{Data source}

Clinicopathological characteristics, Recurrence Score results, and treatments received were obtained from patients' records. Physicians' treatment recommendations prior to Oncotype DX testing were documented on requisition of the assay.

\section{Statistical analyses}

Descriptive statistics were used to summarize clinicopathologic characteristics and Recurrence Score results. T-test/ Mann-Whitney-Wilcoxon (MWW) and Chi-squared/ Fisher's exact tests were used, as appropriate, to compare continuous and categorical parameters, respectively, between patients treated with hormonal therapy alone and those treated with chemohormonal therapy. McNemar's test was used to assess whether the difference between the proportions of patients with hormonal and chemohormonal therapy recommendations (pre-testing) and the proportion of patients who received hormonal and chemohormonal therapy (post-testing) was significant. Logistic regression analyses were used to assess the probability of a treatment change from pre-testing hormonal therapy recommendation to post-testing treatment with chemohormonal therapy and from pre-testing hormonal therapy recommendation to post-testing treatment with chemohormonal therapy as a function of patient's age, tumor size, tumor grade, and the Recurrence Score result. All analyses were conducted using SAS statistical software version 9. 2 (SAS Institute Inc., Cary, NC); $P<0.05$ was considered significant.

\section{Results}

\section{Patient and tumor characteristics}

A total of 116 patients with intermediate Recurrence Score results were included in the analysis (Table 1). Patients were followed for a median (range) of 30 (4-70) months. The majority of patients $(86.1 \%)$ were node negative. Grade distribution was similar to that observed in the general patient population undergoing Oncotype DX testing in Israel (Ben-Baruch et al. 2013). Patients' Recurrence Score results spanned the entire intermediate Recurrence Score category (18-30) and the median Recurrence Score result was 22 (Table 1).

\section{Clinicopathologic characteristics and Recurrence Score results by pre-testing treatment recommendations}

The analysis included 111 patients for whom information about treatment recommendations before Oncotype DX testing and actual treatments received was available. Before testing, 78 patients (70.3\%) were recommended hormonal therapy alone and 33 patients (29.7\%) were recommended chemohormonal therapy. These two groups were not statistically significantly different with respect to age $(P=0.056$; $t$-test $)$, and had statistically significant differences with respect to tumor size $(P=0.0037, t$-test $)$, nodal involvement $(P=0.00013$, Fisher's exact test), grade distribution $(P=0.043$, Chi-squared test), and surgery type (lumpectomy vs. mastectomy, $P=0.0015$, Chi-squared test). In comparison to patients with a pre-testing recommendation of hormonal therapy alone, those with a pretesting recommendation of chemohormonal therapy had 
Table 1 Baseline patient and tumor characteristics

\begin{tabular}{|c|c|}
\hline & $\begin{array}{c}\text { All patients } \\
(N=116)\end{array}$ \\
\hline \multicolumn{2}{|l|}{ Age } \\
\hline Mean (SD), years & $56.2(9.0)$ \\
\hline Median (range), years & $56.5(35-76)$ \\
\hline \multicolumn{2}{|l|}{ Tumor size $^{a}$} \\
\hline Mean (SD), mm & $16.4(6.9)$ \\
\hline Median (range), mm & $15.0(6-55)$ \\
\hline \multicolumn{2}{|l|}{ Nodal status, ${ }^{\text {b }}$ n (\%) } \\
\hline Node negative & $93(86.1)$ \\
\hline Node positive & $15(13.9)$ \\
\hline \multicolumn{2}{|l|}{ Tumor grade, ${ }^{c} n(\%)$} \\
\hline 1 & $16(15.4)$ \\
\hline 2 & $66(63.5)$ \\
\hline 3 & $22(21.2)$ \\
\hline \multicolumn{2}{|l|}{ Type of surgery, ${ }^{d} n(\%)$} \\
\hline Lumpectomy & $96(83.5)$ \\
\hline Mastectomy & $19(16.5)$ \\
\hline \multicolumn{2}{|l|}{ Recurrence Score } \\
\hline Mean (SD) & $22.9(3.7)$ \\
\hline Median (range) & $22(18-30)$ \\
\hline
\end{tabular}

SD standard deviation.

${ }^{\mathrm{a}}$ Tumor size information was unavailable for 1 patient.

${ }^{\mathrm{b}}$ Nodal status information was unavailable for 8 patients.

'Tumor grade information was unavailable for 12 patients.

dSurgery type information was unavailable for 1 patient.

larger tumors, and there were higher proportions of nodepositive patients, grade 3 tumors, and patients who had undergone mastectomy (Table 2).

Notably, the group with a pre-testing chemohormonal therapy recommendation had a statistically significantly higher median Recurrence Score result than the group with a pre-testing hormonal therapy recommendation (24 vs. 22; $P=0.047$; MWW test) (Table 2).

\section{Recurrence Score results and treatments received}

After knowing the Recurrence Score results, 24 patients (21.6\%; 95\% confidence interval [CI], 13.8-29.4\%) received treatment that was different from their pretesting treatment recommendation. Of the 78 patients who were originally recommended hormonal therapy alone, 11 received chemohormonal therapy (14.1\%; 95\% CI, 6.2-22.0\%); of the 33 patients who were originally recommended chemohormonal therapy, 13 received hormonal therapy alone (39.4\%; 95\% CI, 21.8-57.0\%) (Figure 1). Overall, there was virtually no difference between the proportion of patients who were recommended chemohormonal therapy pre-testing and the proportion of patients who received chemohormonal
Table 2 Baseline patient and tumor characteristics for patients with pre-testing recommendations of hormonal therapy alone vs. chemohormonal therapy

\begin{tabular}{|c|c|c|}
\hline & \multicolumn{2}{|c|}{$\begin{array}{l}\text { Physician's treatment recommendation } \\
\text { pre-Oncotype DX testing }\end{array}$} \\
\hline & $\begin{array}{l}\text { Hormonal therapy } \\
\qquad(n=78)\end{array}$ & $\begin{array}{l}\text { Chemohormonal therapy } \\
\qquad(n=33)\end{array}$ \\
\hline \multicolumn{3}{|l|}{$\mathrm{Age}^{\mathrm{a}}$} \\
\hline Mean (SD), years & $57.4(9.0)$ & $53.8(9.1)$ \\
\hline Median (range), years & $57.5(37-76)$ & $55(35-72)$ \\
\hline \multicolumn{3}{|l|}{ Tumor size } \\
\hline Mean (SD), mm & $14.8(5.4)$ & $20.1(9.1)$ \\
\hline Median (range), mm & $14(6-35)$ & $19(8.5-55)$ \\
\hline \multicolumn{3}{|l|}{ Nodal status, ${ }^{c} n(\%)$} \\
\hline Node negative & $71(94.7)$ & $19(63.3)$ \\
\hline Node positive & $4(5.3)$ & $11(36.7)$ \\
\hline \multicolumn{3}{|l|}{ Tumor grade, ${ }^{d} n(\%)$} \\
\hline 1 & $14(20.6)$ & $1(3.2)$ \\
\hline 2 & $42(61.8)$ & $20(64.5)$ \\
\hline 3 & $12(17.7)$ & $10(32.3)$ \\
\hline \multicolumn{3}{|l|}{ Type of surgery, ${ }^{\mathrm{e}} \boldsymbol{n}(\%)$} \\
\hline Lumpectomy & $71(91.0)$ & $22(66.7)$ \\
\hline Mastectomy & $7(9.0)$ & $11(33.3)$ \\
\hline \multicolumn{3}{|l|}{$\begin{array}{l}\text { Recurrence score } \\
\text { result }^{f}\end{array}$} \\
\hline Mean (SD) & $22.5(3.5)$ & $24.1(4.0)$ \\
\hline Median (range) & $22(18-29)$ & $24(18-30)$ \\
\hline
\end{tabular}

$S D$ standard deviation.

${ }^{\mathrm{a}} P=0.056$ ( $t$-test for comparing means).

${ }^{\mathrm{b}} P=0.0037$ ( $t$-test for comparing means). Tumor size information was unavailable for 1 patient in the chemohormonal therapy group.

${ }^{c} P=0.00013$ (Fisher's exact test). Nodal status information was unavailable for

3 patients in the hormonal therapy group and 3 patients in the

chemohormonal therapy group.

${ }^{d} p=0.043$ (Chi-squared test). Grade information was unavailable for 10

patients in the hormonal therapy group and 2 patients in the chemohormonal therapy group.

${ }^{\mathrm{e}} P=0.0015$ (Chi-squared test)

${ }^{\mathrm{f}} P=0.047$ (MWW test).

therapy post-testing (29.7\% before vs. $27.9 \%$ after; $P=0.68$; McNemar's test).

Treatment changes were also analyzed by age ( $\leq 50,>50$ years), tumor size $(\leq 15 \mathrm{~mm},>15 \mathrm{~mm})$, and grade (for patients with grade 2 and 3 tumors). In all the analyzed subgroups, the net change in chemotherapy use (i.e., the difference between the proportion of patients with pre-testing chemohormonal therapy recommendations and the proportion of patients who received chemohormonal therapy post-testing) was nonsignificant ( $P$ values between 0.18 and 0.82 ; McNemar's test). The overall change rate in treatment decisions (from pretesting chemohormonal therapy recommendation to posttesting hormonal therapy treatment and from pre-testing 


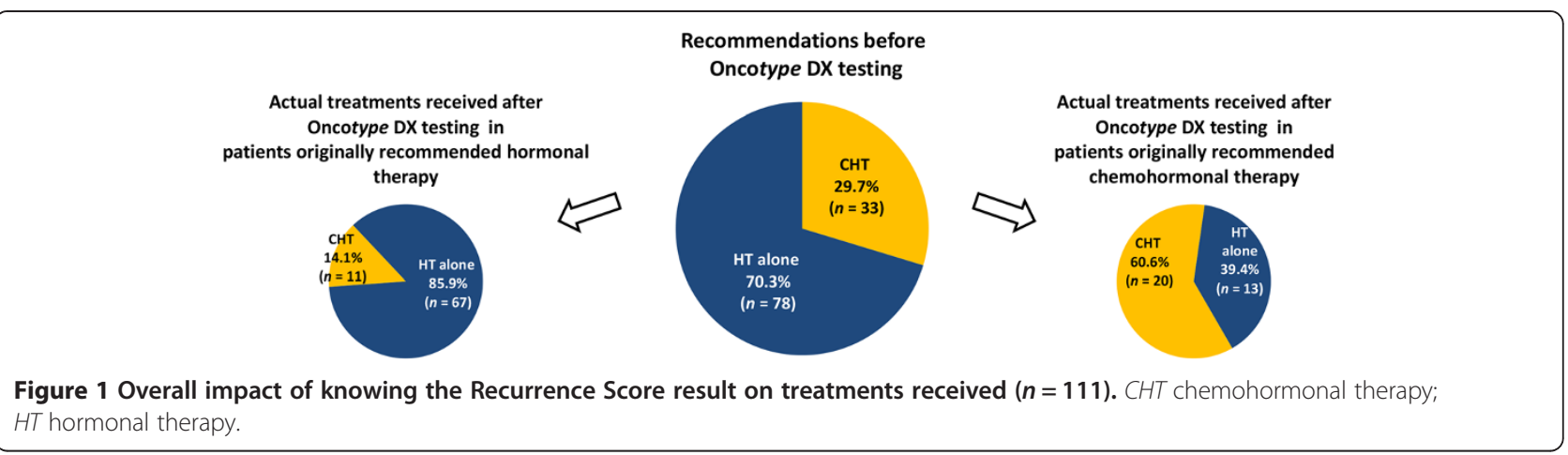

hormonal therapy recommendation to post-testing chemohormonal therapy treatment) was similar in the younger ( $\leq 50$ years) and older ( $>50$ years) age subgroups $(16.7 \%$ [95\% CI, $2.5-30.8 \%$ ] vs. $23.5 \%$ [95\% CI, 14.0-32.9\%]), and in patients with smaller $(\leq 15 \mathrm{~mm})$ and larger $(>15 \mathrm{~mm})$ tumors $(16.9 \%$ [95\% CI, 7.6-26.3\%] vs. $26.7 \%$ [ $95 \% \mathrm{CI}, 13.2-40.1 \%])$. Of the 16 patients with grade 1 tumors, only 1 (6.3\% [95\% CI, $0-30.3 \%])$ had a treatment decision change (from pre-testing hormonal therapy recommendation to receiving chemohormonal therapy post-testing); in patients with grade 2 and grade 3 tumors, the overall change rate was more pronounced and similar $(24.2 \%$ [ $95 \% \mathrm{CI}, 13.2-35.2 \%]$ and $27.3 \%$ [95\% CI, 7.1-47.5\%], respectively).

To explore whether clinicians perceive intermediate Recurrence Score patients in a uniform manner, the cohort was divided into two intermediate Recurrence Score subcategories (the low-intermediate subcategory [Recurrence Score results: $18-25]$ and the high-intermediate subcategory [Recurrence Score results: 26-30]; 25 was used as the cutoff to define the subcategories as it is the cutoff used in the ongoing Oncotype DX phase 3 TAILORx and RxPONDER trials (ClinicalTrials.gov website 2013a; ClinicalTrials.gov website 2013b)), and changes between pre-testing treatment recommendations and post-testing actual treatments received were analyzed for each subcategory separately (Figure 2). Of the 79 patients with lowintermediate Recurrence Score results, 13 (16.5\% [95\% CI, 8.3-24.7\%]) had a change while 11 (34.4\% [95\% CI, 17.9-50.9\%]) of the 32 patients with high-intermediate Recurrence Score results had a change. Notably, in the low-intermediate-Recurrence Score subcategory, the changes were primarily from pre-testing chemohormonal therapy recommendation to post-testing treatment with hormonal therapy alone, and consequently, the overall rate of chemohormonal therapy decreased significantly after knowing the Recurrence Score results (by $58 \%$, from $24.1 \%$ to $10.1 \% ; P=0.002$; McNemar's test). In the highintermediate-Recurrence Score subcategory, the changes were primarily in the opposite direction (from hormonal to chemohormonal therapy), and consequently, the overall rate of chemohormonal therapy increased significantly after knowing the Recurrence Score results (by 64\%, from $43.8 \%$ to $71.9 \% ; P=0.007$; McNemar's test).

To assess the impact of the clinicopathologic parameters and the Recurrence Score results on treatment changes, we modeled the probability of a change between treatment recommendation and actual treatment received as a function of age $(\leq 50,>50$ years), tumor size $(\leq 15 \mathrm{~mm},>15 \mathrm{~mm})$, grade $(1,2$, and 3$)$, and the Recurrence Score subcategory (low-intermediate and high-intermediate, as defined above) for patients with pre-testing hormonal therapy recommendations and for patients with pre-testing chemohormonal therapy recommendations. Possible interaction between the effect of the Recurrence Score subcategory and patients' age, tumor size, or tumor grade (each separately) on the probability of a treatment change was examined by the Breslow Day test. As the effect of the Recurrence Score subcategory was consistent in all subgroups (with the exception of one small subgroup $[\mathrm{n}=14]$ ), and the Breslow Day tests were nonsignificant $(P>0.25)$, only main effects were considered for the logistic regression analyses. For patients with a pre-testing hormonal therapy recommendation, the only significant predictor of a treatment change was highintermediate Recurrence Score subcategory (odds ratio [OR], 73.8 [95\% CI, 8.3-655.2] vs. the low-intermediate subcategory; $P=0.0001$ ). For patients with a pre-testing chemohormonal therapy recommendation, multivariate logistic regression analysis was not technically possible because there were only 33 such patients. For these patients, univariate analysis was performed and demonstrated that the low-intermediate Recurrence Score subcategory was a significant predictor of a treatment change (OR, 22.3 [95\% CI, 2.4-208.8] vs. the high-intermediate subcategory; $P=0.007$ ).

Evaluation of the two subsets of patients with a treatment change (11 patients with a pre-testing hormonal therapy recommendation who were treated with chemohormonal therapy post-testing, and 13 patients with a pre-testing chemohormonal therapy recommendation who were treated with hormonal therapy post-testing) 
a

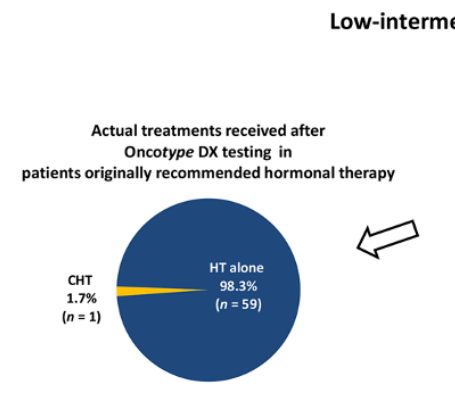

b

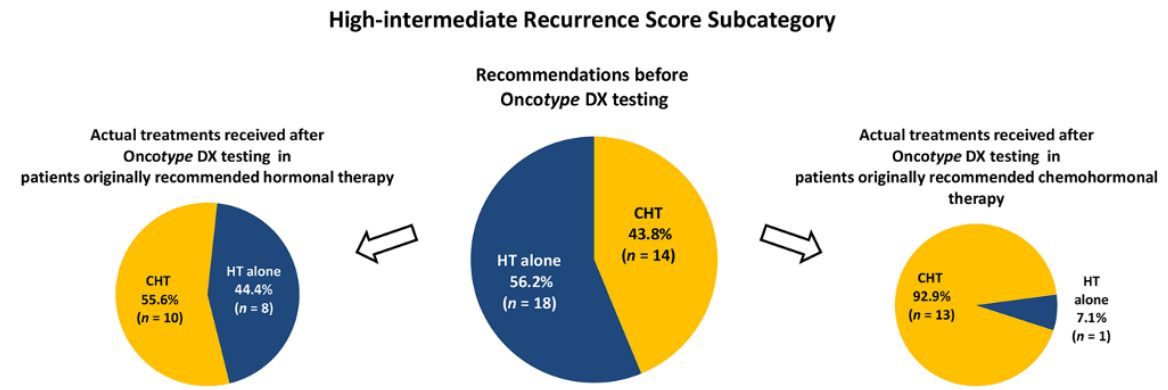

Figure 2 Impact of knowing the Recurrence Score result on treatments received in the low-intermediate Recurrence Score subcategory (Recurrence Score values of $18-25 ; n=79$ ) (a) and in the high-intermediate Recurrence Score subcategory (Recurrence Score values of 26-30; $\boldsymbol{n = 3 2}$ ) (b) CHT chemohormonal therapy; HT hormonal therapy.

revealed no statistically significant differences in clinicopathologic parameters including patients' age, tumor size, nodal status, tumor grade, and type of surgery performed between the groups (although the small sample size limited our ability to draw conclusions) (Table 3). Statistically significant differences between the groups were noted with respect to Recurrence Score results with higher Recurrence Score results in patients with hormonal to chemohormonal therapy change than in patients with the reverse change (median [range] of 28 [23-29] and 20 [18-28], respectively; $P=0.0014$; MWW test) (Table 3).

\section{Discussion}

Oncotype DX testing is routinely used in clinical practice in Israel to support clinical decision making for patients with ER + early invasive breast cancer. The current analysis focused on the impact of intermediate Recurrence Score results on adjuvant treatment decisions in ER + early invasive breast cancer in real-life clinical practice and demonstrated that intermediate results led to a change between pre-testing recommendations and actual treatments received in approximately one-fifth $(21.6 \%)$ of the cohort. The observed changes were in both directions (from hormonal therapy alone to chemohormonal therapy and vice versa) with no significant net change in chemotherapy use $(30 \%$ recommended pre-testing vs. $28 \%$ actually used). Unlike low- and high-Recurrence Score patients, for whom the impact of the Recurrence
Score results on treatment decisions has been shown to be consistent across studies (increased and decreased chemotherapy use, respectively) (Oratz et al. 2007; Klang et al. 2010; Lo et al. 2010; Ademuyiwa et al. 2011; Geffen et al. 2011; Oratz et al. 2011; Albanell et al. 2012; Eiermann et al. 2012; Gligorov et al. 2012; Albanell et al. 2013; Holt et al. 2013), in intermediate-Recurrence Score patients, the overall impact of the Recurrence Score results on chemotherapy use is not consistent across studies and the overall net change ranged from an increased use of chemotherapy by more than $85 \%$ to a decreased use of chemotherapy by more than $40 \%$ (Oratz et al. 2007; Klang et al. 2010; Lo et al. 2010; Ademuyiwa et al. 2011; Geffen et al. 2011; Oratz et al. 2011; Albanell et al. 2012; Eiermann et al. 2012; Gligorov et al. 2012; Albanell et al. 2013; Holt et al. 2013 ). These results are consistent with the hypothesis that clinicians weigh additional factors (e.g., the exact Recurrence Score value and not the Recurrence Score category, age, grade, nodal status, etc.) in considering chemotherapy for intermediateRecurrence Score patients.

Our study evaluated the factors that may influence changes in treatment decisions in intermediate-Recurrence Score patients. Traditional parameters such as patient's age, tumor size, and tumor grade, did not have a statistically significant impact on the change in chemotherapy use from pre- to post-Oncotype DX testing. Notably, the Recurrence Score itself did have a significant impact. In patients who had a treatment change (pre-testing 
Table 3 Clinicopathologic and Recurrence Score results in patients with a treatment change $(n=24)$

\begin{tabular}{|c|c|c|}
\hline & \multicolumn{2}{|c|}{ Type of treatment change } \\
\hline & $\begin{array}{l}\text { Pre-testing: HT. } \\
\text { Post-testing: CHT. } \\
\qquad(n=11)\end{array}$ & $\begin{array}{l}\text { Pre-testing: CHT. } \\
\text { Post-testing: HT. } \\
\quad(n=13)\end{array}$ \\
\hline \multicolumn{3}{|l|}{$\mathrm{Age}^{\mathrm{a}}$} \\
\hline Mean (SD), years & $54.2(3.4)$ & $55.1(9.5)$ \\
\hline Median (range), years & $54(46-58)$ & $56(35-72)$ \\
\hline \multicolumn{3}{|l|}{ Tumor size ${ }^{b}$} \\
\hline Mean (SD), mm & $15.6(5.7)$ & $20.4(7.6)$ \\
\hline Median (range), mm & $14(10-28)$ & $20.5(10-32)$ \\
\hline \multicolumn{3}{|l|}{ Nodal status, ${ }^{c} n(\%)$} \\
\hline Node negative & $10(100)$ & $8(72.7)$ \\
\hline Node positive & $0(0)$ & $3(27.3)$ \\
\hline \multicolumn{3}{|l|}{ Tumor grade, ${ }^{\mathrm{d}} \boldsymbol{n}(\%)$} \\
\hline 1 & $1(9.1)$ & $0(0)$ \\
\hline 2 & $8(72.7)$ & $7(63.6)$ \\
\hline 3 & $2(18.2)$ & $4(36.4)$ \\
\hline \multicolumn{3}{|l|}{ Type of surgery, $n$ (\%) } \\
\hline Lumpectomy & $10(90.9)$ & $9(69.2)$ \\
\hline Mastectomy & $1(9.1)$ & $4(30.8)$ \\
\hline \multicolumn{3}{|l|}{ Recurrence Score result $^{f}$} \\
\hline Mean (SD) & $27.3(1.7)$ & $21.1(3.0)$ \\
\hline Median (range) & $28(23-29)$ & $20(18-28)$ \\
\hline \multicolumn{3}{|c|}{$\begin{array}{l}\text { CHT chemohormonal therapy; } H T \text { hormonal therapy; } S D \text { standard deviation. } \\
{ }^{\mathrm{a}} P=0.76 \text { ( } t \text {-test for comparing means). } \\
{ }^{\mathrm{b}} P=0.11 \text { (t-test for comparing means). Tumor size information was unavailable } \\
\text { for } 1 \text { patient in the chemohormonal to hormonal therapy group. } \\
{ }^{\mathrm{c}} P=0.21 \text { (Fisher's exact test). Nodal status information was unavailable for } 1 \\
\text { patient in the hormonal therapy to chemohormonal therapy group and } 2 \\
\text { patients in the chemohormonal to hormonal therapy group. } \\
{ }^{\mathrm{d}} P=0.64 \text { (Fisher's exact test). Grade information was unavailable for } 2 \text { patients } \\
\text { in the chemohormonal to hormonal therapy group. } \\
{ }^{{ }^{e} P} P=0.33 \text { (Fisher's exact test). } \\
{ }^{\mathrm{f}} P=0.0014 \text { (MWW test). }\end{array}$} \\
\hline
\end{tabular}

recommendation vs. actual treatment received), higher intermediate Recurrence Score results were significantly associated with a decision to treat with chemohormonal therapy, suggesting that clinicians evaluate the Recurrence Score as a continuous parameter and do not consider all intermediate-Recurrence Score patients as having the same risk of recurrence. Also, in an analysis of treatment change by Recurrence Score subcategory (using a cutoff of 25, which is the cutoff used in the ongoing Oncotype DX phase 3 TAILORx and RxPONDER trials that were designed to assess chemotherapy benefit in node-negative patients with Recurrence Score results between 12 and 25 and node-positive patients with results $\leq 25$, respectively (ClinicalTrials.gov website 2013a; ClinicalTrials.gov website 2013b)), the treatment changes were statistically significant with a decrease in chemotherapy use in the low-intermediate subcategory $(58 \%$ relative decrease) and an increase in chemotherapy use in the high-intermediate subcategory (64\% relative increase). This novel finding was also supported by a logistic regression analysis demonstrating the statistical significance of the Recurrence Score subcategory as a predictor of a treatment change.

Oncotype DX testing has been shown to increase clinicians' confidence in their treatment decisions (Lo et al. 2010; Albanell et al. 2012; Eiermann et al. 2012); only one study analyzed this increase by patients' Recurrence Score results, and demonstrated that a higher proportion of clinicians reported increased confidence when the patients had low or high Recurrence Score results than when the patients had intermediate Recurrence Score results (Eiermann et al. 2012). In addition, several studies have recently shown that patients experienced significantly lower conflict about their treatment decisions and decreased situational anxiety after receiving their Recurrence Score results (Lo et al. 2010; In et al. 2011; Eiermann et al. 2012). Only one study evaluated the impact of intermediate Recurrence Score results on patients and found that among patients who preferred a passive role in their care (but not among those who preferred an active/shared role), those with intermediate Recurrence Score results had higher cancer-related distress than patients with low/high Recurrence Score (Sulayman et al. 2012), possibly reflecting the uncertainty associated with the potential benefit of chemotherapy in these patients. Thus, it may be of interest to assess the impact of intermediate Recurrence Score results (as a continuous parameter) on clinicians' confidence as well as on patients' psychosocial status.

The limitations of this study include its retrospective design and a relatively small sample size. In addition, since this was a single-center study, its ability to represent treatment patterns in the general breast cancer patient population in Israel may be limited.

In summary, our findings demonstrate that intermediate Recurrence Score results are not perceived in a uniform manner by clinicians, but rather provide clinically relevant information that impacts adjuvant treatment decisionmaking in patients with ER + early invasive breast cancer.

\section{Competing interest}

The authors declare that they have no competing interest.

\section{Authors' contribution}

GF and MM conceptualized and designed the study, including acquisition of data, setting the strategy and methods. GF and MM interpreted the data, and participated in drafting the manuscript and revising it critically for important intellectual content. GF and MM read and approved the final manuscript.

\section{Acknowledgement}

The work was supported by Genomic Health, Inc. and Teva Pharmaceutical Industries, Ltd. Medical writing assistance was provided by Avital Bareket-Samish, PhD, of Biolnsight Ltd and was funded by Teva Pharmaceutical Industries, Ltd. 
Received: 22 January 2014 Accepted: 23 January 2014

\section{Published: 6 February 2014}

\section{References}

Ademuyiwa FO, Miller A, O'Connor T, Edge SB, Thorat MA, Sledge GW, Levine E, Badve S (2011) The effects of oncotype DX recurrence scores on chemotherapy utilization in a multi-institutional breast cancer cohort. Breast Canc Res Treat 126(3):797-802, doi:10.1007/s10549-010-1329-6

Albain KS, Barlow WE, Shak S, Hortobagyi GN, Livingston RB, Yeh IT, Ravdin P, Bugarini R, Baehner FL, Davidson NE, Sledge GW, Winer EP, Hudis C, Ingle JN, Perez EA, Pritchard KI, Shepherd L, Gralow JR, Yoshizawa C, Allred DC, Osborne CK, Hayes DF (2010) Prognostic and predictive value of the 21-gene recurrence score assay in postmenopausal women with node-positive, oestrogen-receptor-positive breast cancer on chemotherapy: a retrospective analysis of a randomised trial. Lancet Oncol 11(1):55-65, doi:10.1016/S14702045(09)70314-6

Albanell J, Gonzalez A, Ruiz-Borrego M, Alba E, Garcia-Saenz JA, Corominas JM, Burgues O, Furio V, Rojo A, Palacios J, Bermejo B, Martinez-Garcia M, Limon ML, Munoz AS, Martin M, Tusquets I, Rojo F, Colomer R, Faull I, Lluch A (2012) Prospective transGEICAM study of the impact of the 21-gene recurrence score assay and traditional clinicopathological factors on adjuvant clinical decision making in women with estrogen receptor-positive (ER+) node-negative breast cancer. Ann Oncol 23:625-631, doi:10.1093/annonc/mdr278

Albanell J, Gligorov J, Holt S, Blohmer J, Eiermann W, Svedman C (2013) Pooled analysis of 4 European studies assessing the impact of Oncotype DX on treatment decisions. In: Paper presented at the the 13th St. Gallen International Breast Cancer Conference 2013 St, Gallen, Switzerland

Asad J, Jacobson AF, Estabrook A, Smith SR, Boolbol SK, Feldman SM, Osborne MP, Boachie-Adjei K, Twardzik W, Tartter PI (2008) Does oncotype DX recurrence score affect the management of patients with early-stage breast cancer? Am J Surg 196(4):527-529, S0002-9610(08)00490-X, doi:10.1016/j.amjsurg.2008.06.021

Ben-Baruch N, Rizel S, Yerushalmi R, Nisenbaum B, Gabizon A, Steiner M, Geffen DB, Evron E, Liebermann N, Stemmer SM (2013) Differences in Recurrence Score results between luminal $A$ and luminal $B$ breast cancer subtypes. Paper presented at the the 13th St. Gallen International Breast Cancer Confernece 2013, St. Gallen, Switzerland

ClinicalTrials.gov website (2013a) Description of the TAILORx trial. http:// www.clinicaltrials.gov/ct2/show/NCT00310180. Accessed 1 January

ClinicalTrials.gov website (2013b) Description of the RxPONDER trial. http://www. clinicaltrials.gov/ct2/show/NCT01272037. Accessed 1 January

de Boer RH, Baker C, Speakman D, Mann B (2011) Australian decision impact study: The impact of Oncotype DX Recurrence Score (RS) on adjuvant treatment decisions in hormone receptor positive $(\mathrm{HR}+)$, node negative (N0) and node positive $(\mathrm{N}+)$ early stage breast cancer (ESBC) in the multidisciplinary clinic (MDC). Paper presented at the San Antonio Breast Cancer Symposium (SABCS), San Antonio, TX

Dowsett M, Cuzick J, Wale C, Forbes J, Mallon EA, Salter J, Quinn E, Dunbier A, Baum M, Buzdar A, Howell A, Bugarini R, Baehner FL, Shak S (2010) Prediction of risk of distant recurrence using the 21-gene recurrence score in node-negative and node-positive postmenopausal patients with breast cancer treated with anastrozole or tamoxifen: a TransATAC study. J Clin Oncol 28 (11):1829-1834, doi:10.1200/JCO.2009.24.4798

Eiermann W, Rezai M, Kummel S, Kuhn T, Warm M, Friedrichs K, Schneeweiss A, Markmann S, Eggemann H, Hilfrich J, Jackisch C, Witzel I, Eidtmann H, Bachinger A, Hell S, Blohmer J (2012) The 21-gene recurrence score assay impacts adjuvant therapy recommendations for ER-positive, node-negative and node-positive early breast cancer resulting in a risk-adapted change in chemotherapy use. Ann Oncol 24(3):618-624, doi:10.1093/annonc/mds512

Geffen DB, Abu-Ghanem S, Sion-Vardy N, Braunstein R, Tokar M, Ariad S, Delgado B, Bayme M, Koretz M (2011) The impact of the 21-gene recurrence score assay on decision making about adjuvant chemotherapy in early-stage estrogen-receptorpositive breast cancer in an oncology practice with a unified treatment policy. Ann Oncol 22(11):2381-2386, doi:10.1093/annonc/mdq769

Gligorov J, Pivot XB, Naman HL, Jacot W, Spaeth D, MJ L, Largillier R, Sautiere $J$, de Roquancourt A, Pomel C, Rouanet P, Rouzier R, Penault-Llorca FM (2012) Prospective study of the impact of using the 21-gene recurrence score assay on clinical decision making in women with estrogen receptorpositive, HER2negative, early-stage breast cancer in France. In: Paper presented at the American Society of Clinical Oncology (ASCO) Annual Meeting Chicago, IL
Goldstein $\sqcup$, Gray R, Badve S, Childs BH, Yoshizawa C, Rowley S, Shak S, Baehner FL, Ravdin PM, Davidson NE, Sledge GW Jr, Perez EA, Shulman LN, Martino S, Sparano JA (2008) Prognostic utility of the 21-gene assay in hormone receptorpositive operable breast cancer compared with classical clinicopathologic features. J Clin Oncol 26(25):4063-4071, doi:10.1200/JCO.2007.14.4501

Habel LA, Shak S, Jacobs MK, Capra A, Alexander C, Pho M, Baker J, Walker M, Watson D, Hackett J, Blick NT, Greenberg D, Fehrenbacher L, Langholz B, Quesenberry CP (2006) A population-based study of tumor gene expression and risk of breast cancer death among lymph node-negative patients. Breast Cancer Res 8(3):R25, doi:10.1186/bcr1412

Henry LR, Stojadinovic A, Swain SM, Prindiville S, Cordes R, Soballe PW (2009) The influence of a gene expression profile on breast cancer decisions. J Surg Oncol 99(6):319-323, doi:10.1002/jso.21244

Holt S, Bertelli G, Humphreys I, Valentine W, Durrani S, Pudney D, Rolles M, Moe M, Khawaja S, Sharaiha Y, Brinkworth E, Whelan S, Jones S, Bennett H, Phillips CJ (2013) A decision impact, decision conflict and economic assessment of routine Oncotype DX testing of 146 women with node-negative or pNImi, ER-positive breast cancer in the UK. Br J Cancer 108(11):2250-2258, doi:10.1038/bjc.2013.207

In R, Yamauchi H, Yoshida A, Yagata H, Nakagawa C, Ohde S, Takei H, Nakamura S (2011) Patient satisfaction analysis for decision impact of the 21-gene Recurrence Score (RS) assay. Paper presented at the Global Breast Cancer Conference (GBCC), Seoul, Korea

Kamal AH, Loprinzi CL, Reynolds C, Dueck AC, Geiger XJ, Ingle JN, Carlson RW, Hobday TJ, Winer EP, Goetz MP (2011) Breast Medical Oncologists' Use of Standard Prognostic Factors to Predict a 21-Gene Recurrence Score. Oncologist 16(10):1359-1366, doi:10.1634/theoncologist.2011-0048

Klang SH, Hammerman A, Liebermann N, Efrat N, Doberne J, Hornberger J (2010) Economic implications of 21-gene breast cancer risk assay from the perspective of an Israeli-managed health-care organization. Value Health 13(4):381-387, doi:10.1111/j.1524-4733.2010.00724.x

Lo SS, Mumby PB, Norton J, Rychlik K, Smerage J, Kash J, Chew HK, Gaynor ER, Hayes DF, Epstein A, Albain KS (2010) Prospective multicenter study of the impact of the 21-gene recurrence score assay on medical oncologist and patient adjuvant breast cancer treatment selection. J Clin Oncol 28(10):1671-1676, doi:10.1200/JCO.2008.20.2119

Mamounas EP, Tang G, Paik S, FL B, Liu Q, Jeong J-H, Kim S-R, Butler SM, Jamshidian F, Cherbavaz DB, Sing AP, Shak S, Julian TB, Lembersky BC, Wickerham DL, Costantino JP, Wolmark N (2012) Association between the 21-Gene Recurrence Score (RS) and benefit from adjuvant paclitaxel (Pac) in node-positive $(\mathrm{N}+)$, ER-positive breast cancer patients (pts): Results from NSABP B-28. Paper presented at the San Antonio Breast Cancer Symposium (SABCS), San Antonio, TX, December 4-8

Oratz R, Paul D, Cohn AL, Sedlacek SM (2007) Impact of a commercial reference laboratory test recurrence score on decision making in early-stage breast cancer. J Oncol Pract 3(4):182-186, doi:10.1200/JOP.0742001

Oratz R, Kim B, Chao C, Skrzypczak S, Ory C, Bugarini R, Broder M (2011) Physician survey of the effect of the 21 -gene recurrence score assay results on treatment recommendations for patients with lymph node-positive, estrogen receptor-positive breast cancer. J Oncol Pract 7(2):94-99, doi:10.1200/ JOP.2010.0000463677813

Paik S, Shak S, Tang G, Kim C, Baker J, Cronin M, Baehner FL, Walker MG, Watson D, Park T, Hiller W, Fisher ER, Wickerham DL, Bryant J, Wolmark N (2004) A multigene assay to predict recurrence of tamoxifen-treated, node-negative breast cancer. $\mathrm{N}$ Engl J Med 351(27):2817-2826, doi:10.1056/NEJMoa041588

Paik S, Tang G, Shak S, Kim C, Baker J, Kim W, Cronin M, Baehner FL, Watson D, Bryant J, Costantino JP, Geyer CE Jr, Wickerham DL, Wolmark N (2006) Gene expression and benefit of chemotherapy in women with node-negative, estrogen receptor-positive breast cancer. J Clin Oncol 24(23):3726-3734, doi:10.1200/JCO.2005.04.7985

Rayhanabad JA, Difronzo LA, Haigh PI, Romero L (2008) Changing paradigms in breast cancer management: introducing molecular genetics into the treatment algorithm. Am Surg 74(10):887-890

Sulayman N, Spellman E, Graves KD, Peshkin BN, Isaacs C, Schwartz MD, O'Neill SC (2012) Psychosocial and Quality of Life in Women Receiving the 21-Gene Recurrence Score Assay: The Impact of Decision Style in Women with Intermediate RS. J Canc Epidemiol:728290, Doi:10.1155/2012/728290

Toi M, Iwata H, Yamanaka T, Masuda N, Ohno S, Nakamura S, Nakayama T, Kashiwaba M, Kamigaki S, Kuroi K (2010) Clinical significance of the 21-gene signature (Oncotype DX) in hormone receptor-positive early stage primary 
Yamauchi H, Nakagawa C, Yamashige S, Takei H, Yagata H, Yoshida A, Chien R, Hornberger J, Nakamura S (2011) Decision impact and economic evaluation of the 21-gene Recurrence Score (RS) assay for physicians and patients in Japan. Eur J Cancer 47(Suppl1):S376

doi:10.1186/2193-1801-3-71

Cite this article as: Fried and Moskovitz: Treatment decisions in estrogen receptor-positive early breast cancer patients with intermediate oncotype DX recurrence score results. SpringerPlus 2014 3:71.

Submit your manuscript to a SpringerOpen ${ }^{\circ}$ journal and benefit from:

- Convenient online submission

Rigorous peer review

- Immediate publication on acceptance

- Open access: articles freely available online

- High visibility within the field

- Retaining the copyright to your article

Submit your next manuscript at springeropen.com 